
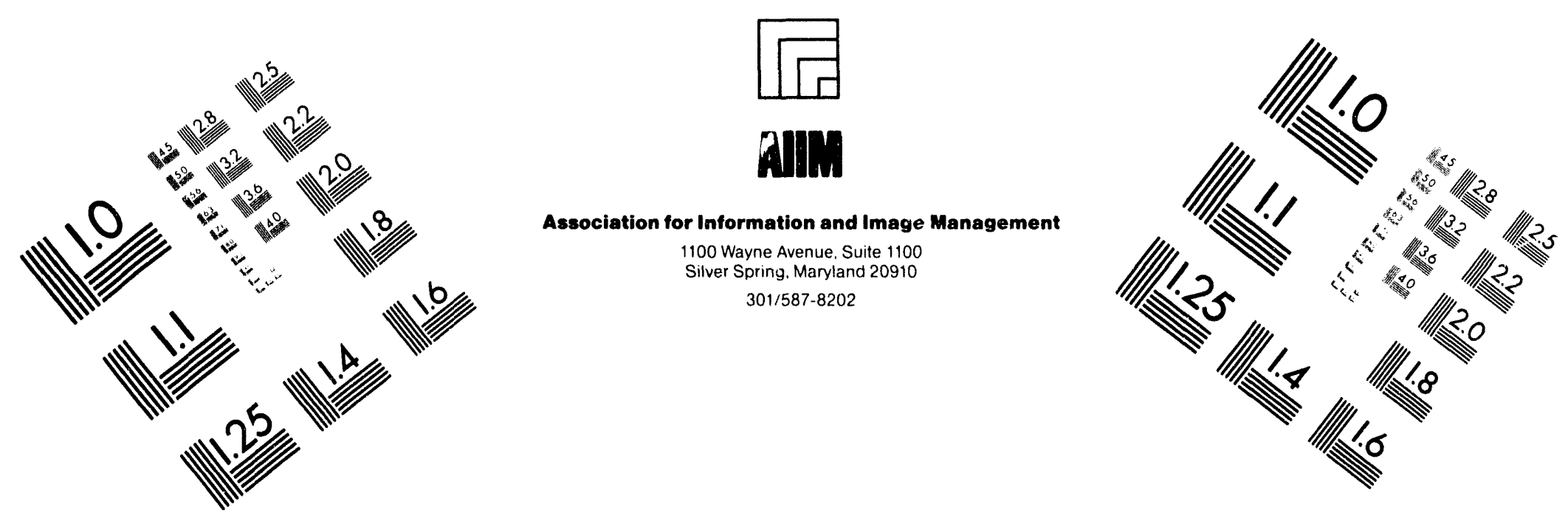

\title{
Centimeter
}

$\begin{array}{llllllllllllllll}1 & 2 & 3 & 4 & 5 & 6 & 7 & 8 & 9 & 10 & 11 & 12 & 13 & 14 & 15 & \mathrm{~mm}\end{array}$

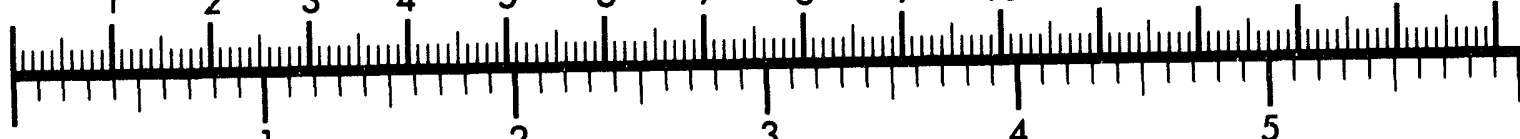
Inches

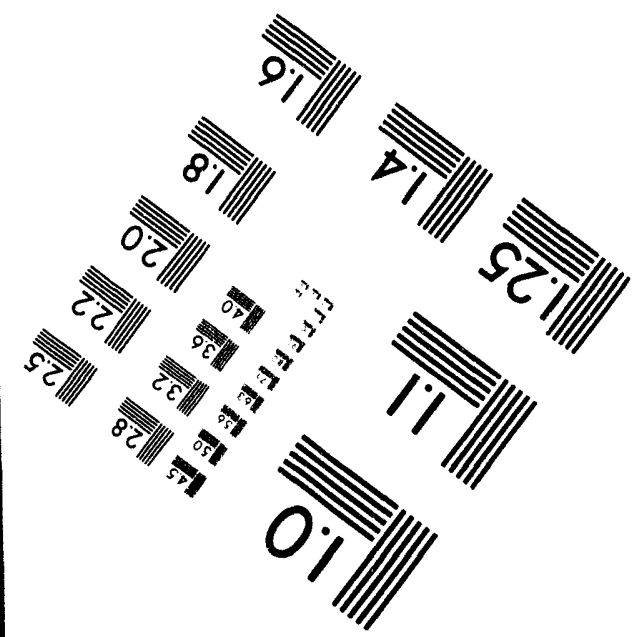

MANUFACTURED TO AIIM STANDARDS

BY APPLIED IMAGE, INC.

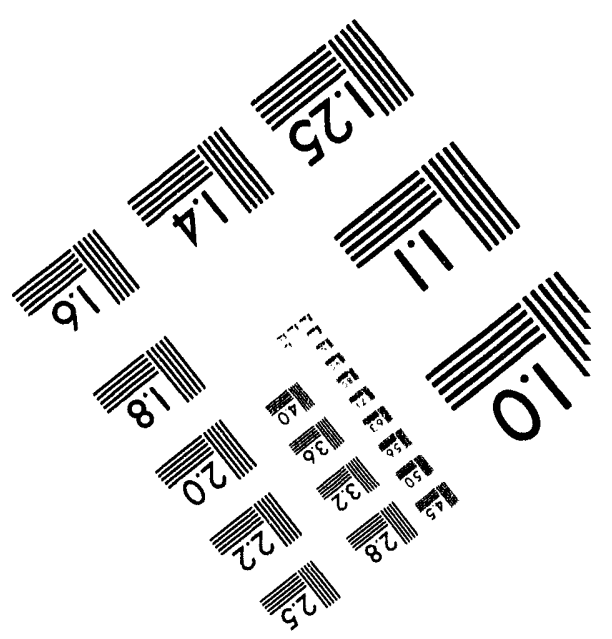



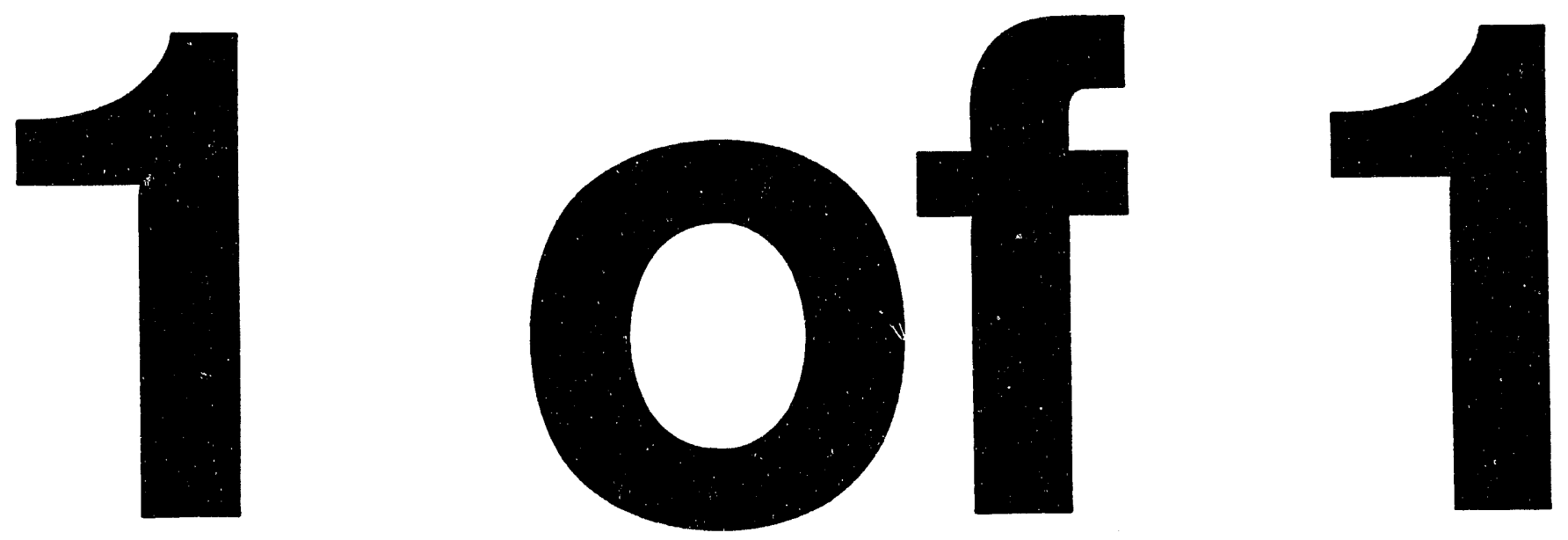


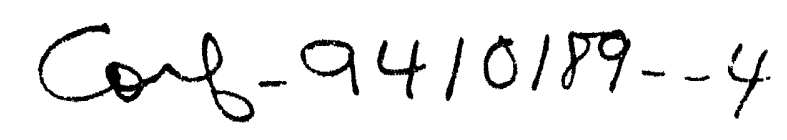

Application of a Dimensionless Parameter Model for Laser Beam Welding

\author{
Phillip W. Fuerschbach \\ Sandia National Laboratories \\ Albuquerque, New Mexico 87185-0340 \\ pwfuers@sandia.gov
}

\begin{abstract}
A new dimensionless parameter model for continuous wave laser welding that relates the size of the weld to the energy absorbed by the part is described. The model has been experimentally validated previously through calorimetric determinations of the net heat input and metallographic measurements of the weld size. It will be shown that both the melting efficiency and energy transfer efficiency for LBW are quite variable and need to be considered when selecting processing conditions. Specific applications will be detailed in order to observe the simplicity and value of the model in laser weld process development. It will be shown that by using certain dimensionless parameters one can determine the energy transfer efficiency and thereby correctly select processing conditions that more fully utilize the available laser output power. In applications where minimizing heat input to the surrounding weldment is paramount, the dimensionless parameters can be used to select conditions that maxinuize melting efficiency.
\end{abstract}

\title{
Introduction
}

Laser Beam Welding (LBW) is a manufacturing process that continues to expand into new industries and applications because of it's advantages in achieving deep weld penetration and in minimizing heat input. For the applications engineer to decide on the cost effectiveness of the LBW process, important processing details must be examined before the laser can be specified. To determine the required functional characteristics of the laser for an application, one must consider the production feedrates to be obtained, the size of the fusion zone to be melted, the thermal properties of the materials, and the process efficiencies. To quantify the above factors for LBW without experimental validation, some LBW experimentalists have found the line source model given by Swift-Hook and Gick (Ref. 1)to be valuable. However the applicability of the Swift-Hook and Gick dimensionless parameter model is limited to through-thickness keyhole type welds.

In a multi-year program at Sandia an extensive series of calorimetric measurements of the heat input absorbed by the workpiece during Fartial penetration laser beam welding has been completed. These results have yielded a dimensionless parameter model (Ref. 2)that can be used to quantify the efficiencies ${ }^{1}$ in laser beam welding. The experimental basis for the model will

1 For laser welding, energy transfer efficiency is defined as the ratio of the heat absorbed by the workpiece to the incident laser energy. Melting efficiency is defined as the ratio of the heat necessary to just melt the fusion zone to the heat absorbed by the workpiece. 
not be presented here but instead several examples will be given which will illustrate the utility of this type analysis to laser welding users.

Dimensional Analysis

It has been well established with processes such as fluid flow in pipes that a complex physical process can often be simply formulated as a relationship between specific dimensionless parameters. These dimensionless parameters are groups of the actual process variables that are known to control the process. In laser welding, the mathematical relationship between variables like material, travel speed, and power can be readily determined by combining the important welding process variables into just two dimensionless parameters. The dimensionless parameter model that has proven valuable in characterizing partial penetration laser beam welding is illustrated in Fig. 1. The dimensionless parameters that are given in Fig. 1 are $R y$, after N.N. Rykalin (Ref. 3) and $C h$, after N. Christensen (Ref. 4) who both did important early work that led to the origination of these parameters. The parameters are defined as follows:

$$
\begin{gathered}
R y=\frac{q_{i} v}{\alpha^{2} \delta h} \\
C h=\frac{v^{2} A}{\alpha^{2}}
\end{gathered}
$$

where: $\quad q_{i}=$ net power into the workpiece

$v=$ travel speed

$\alpha=$ the thermal diffusivity at the liquidus temperature

$\delta h=$ the enthalpy of melting

$A=$ the weld cross-sectional area

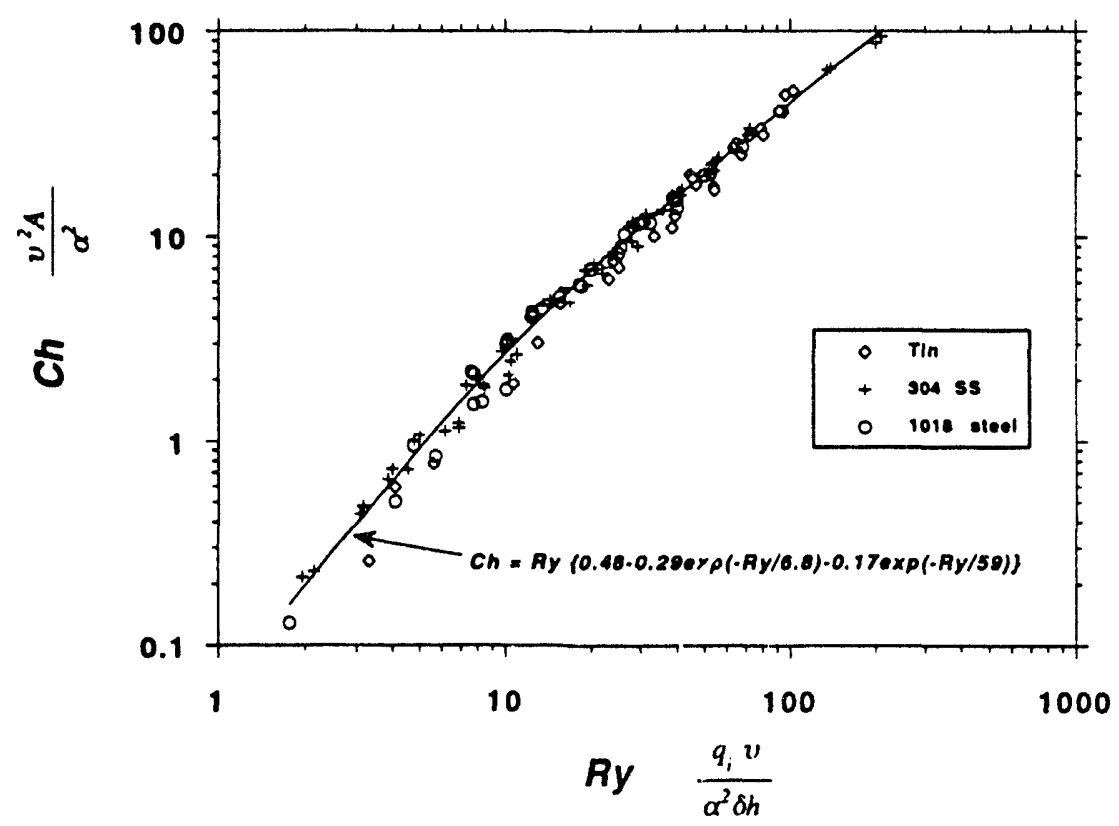

Fig. 1-Dimensionless parameter model for partial penetration continuous power laser welding. 
There are several important things to note about the terms contained in $R y$ and $C h$. The net power into the workpiece, $q_{i}$, is that fraction of the laser output power incident on the weld joint that is actually absorbed. One should also note that unlike other dimensionless parameter models for welding, the value of thermal diffusivity used in this model is taken at the liquid metal temperature. In addition, because this model does not distinguish weld penetration but instead determines the total weld size $(A)$, the model does not require a specific laser beam irradiance to be valid.

\section{Example \#1}

To demonstrate the validity of this model we will start with an example of a representative weld plotted on Fig. 1. The weld was made with a slow axial flow $\mathrm{CO} 2$ laser in the continuous wave $(\mathrm{CW})$ mode. We will treat this weld for the example as if we do not know $q i$, the calorimetric measured power. The following information would typically be known about a weld:

$$
\begin{array}{ll}
\text { Material: } & 304 \text { stainless steel } \\
\text { Enthalpy: } & \delta h=8.7 \mathrm{~J} / \mathrm{mm}^{3} \text { (Ref. 5) } \\
\text { Thermal Diff.: } & \alpha=5.7 \mathrm{~mm}^{2} / \mathrm{s} \text { (Ref. 6) } \\
\text { Output Power: } & q 0=917 \mathrm{~W} \\
\text { Travel Speed: } & v=15.2 \mathrm{~mm} / \mathrm{s}
\end{array}
$$

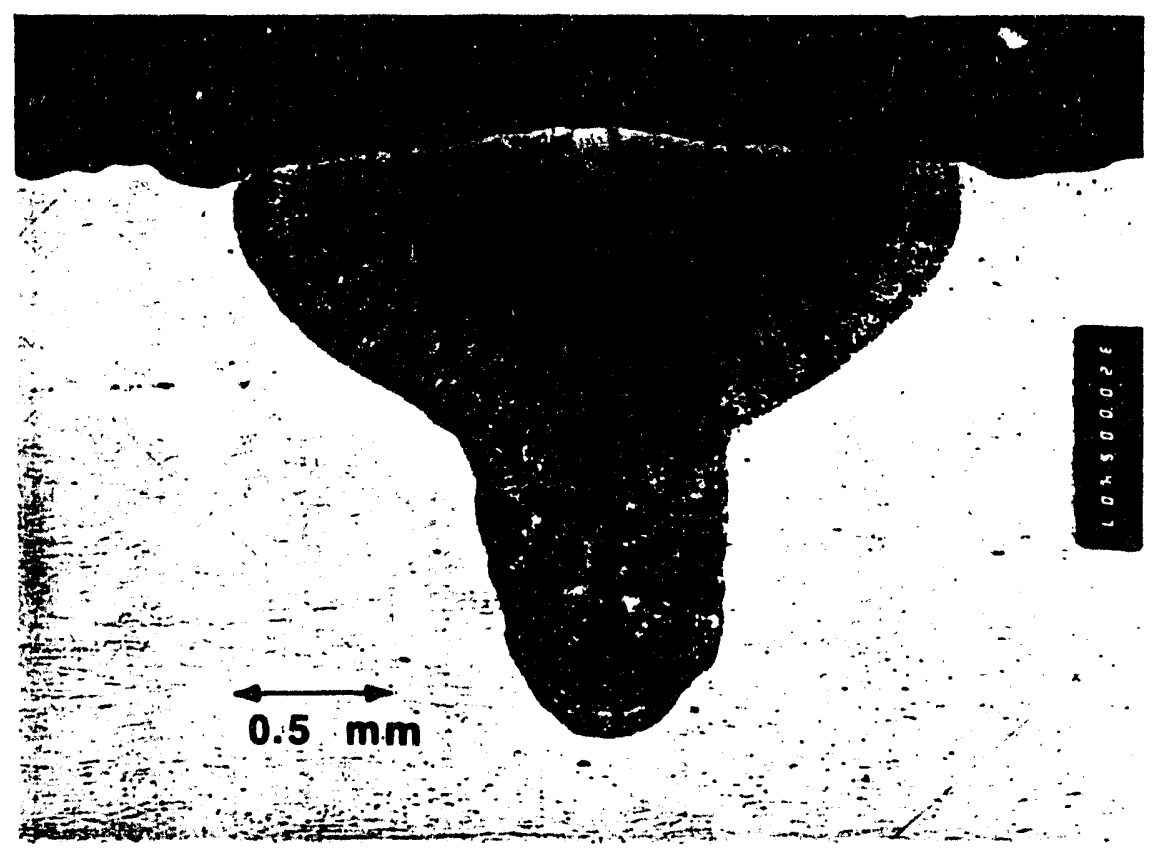

Fig 2-Metallographic cross-section of CW CO2 laser weld used in Example \# 1.

Now if one metallographically sections the weld (see Fig. 2) and then measures the crosssectional weld area with a planimeter we can calculate the first dimensionless parameter as follows:

$$
C h=\frac{v^{2} A}{\alpha^{2}}=\frac{(15.2)^{2}(2.42)}{(5.7)^{2}}=\underline{17.2}
$$


Referring back to Fig. 1, we can either calculate the second dimensionless parameter $R y$ using the equation given there, or simply determine it graphically. Using the resulting value of Ry we can next estimate the net power absorbed by the workpiece as follows:

$$
\begin{aligned}
R y & =\frac{43.1}{2}=\frac{q_{i} v}{\alpha^{2} \delta h} \\
\text { rearranging: } \quad q_{i} & =\frac{R y \alpha^{2} \delta h}{v}=\frac{(43.1)(5.7)^{2}(8.7)}{(15.2)} \\
q_{i} & =\underline{801 W}
\end{aligned}
$$

This estimated value of $q_{i}$ is reasonably close to the calorimetrically measured value of $777 \mathrm{~W}$. Since $q_{i}$ is known, it is a simple matter to calculate the energy transfer efficiency $\left(\eta_{t}\right)$ :

$$
\eta_{1}=\frac{q_{i}}{q_{0}}=\frac{801}{917}=\underline{0.87}
$$

Another useful feature of this model is that once $R y$ and $C h$ have been determined one can easily calculate the melting efficiency $\left(\eta_{m}\right)$ as shown below:

$$
\eta_{m}=\frac{C h}{R y}=\frac{(17.2)}{(43.1)}=\underline{0.40}
$$

The above example illustrates the straightforward manner in which two important figures of merit for the laser welding process can be determined with the dimensionless parameter model given in Fig. 1.

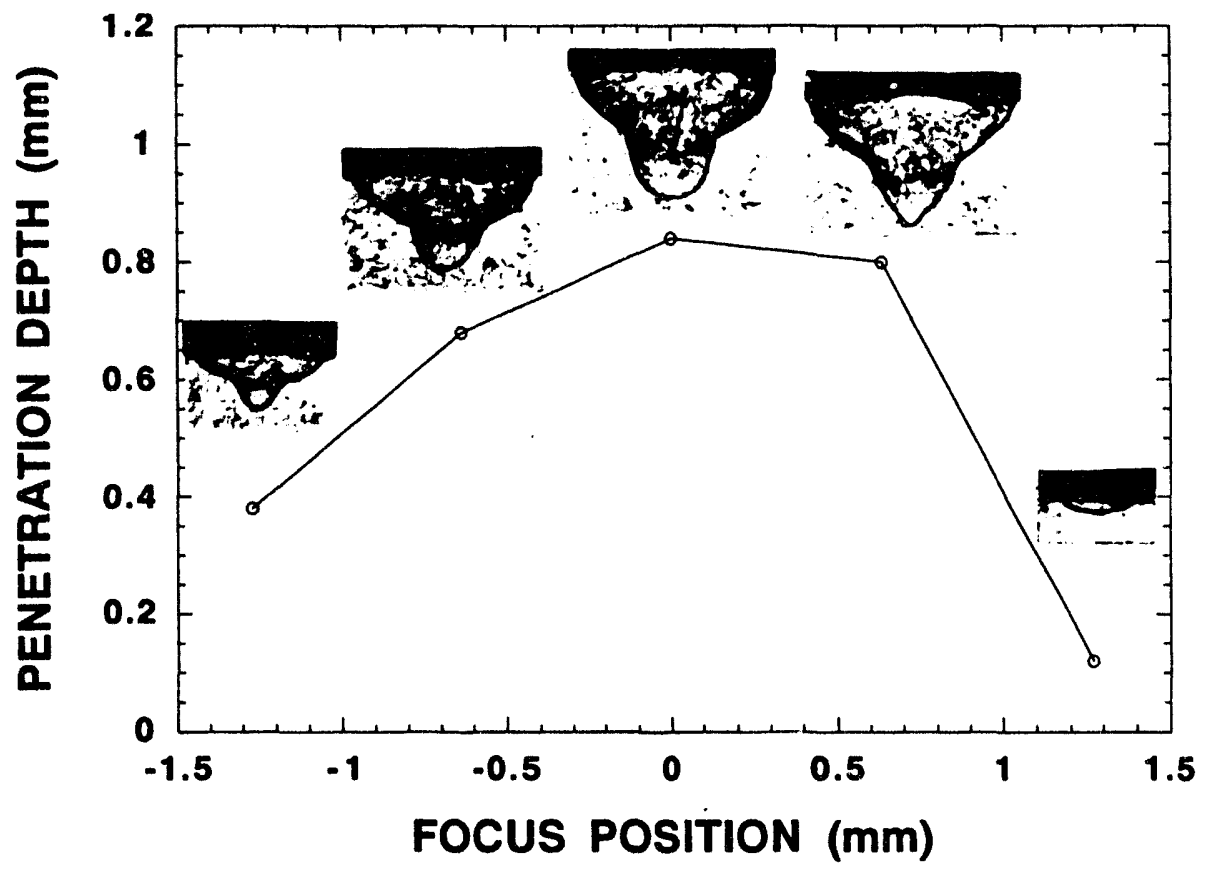

Fig. 3-Effect of lens position on weld depth and area for CW CO2 laser welding with a 5.0 in lens.. 
Example \#2

It is often beneficial to determine the ideal laser focus position for welding by making a series of bead on plate welds at a given power and varying the lens to workpiece distance for each weld. If the welds are made near the focal plane of the lens, subsequent examination of the welds will reveal a symmetry about the highest intensity weld. Such a series of welds are illustrated in Fig. 3 where the resulting penetration depth is plotted against the corresponding focus position. These welds were made with the same laser used in example \#1 and also on 304SS. Also given in Fig. 3 is the metallographic cross-section corresponding to each of the five welds. From the metallographic photos, the weld area was measured and calculations were made to determine the net power absorbed by the workpiece just as in Example \#1. The results of these calculations for each weld are illustrated in Fig. 4 where the energy transfer efficiency is given for each of the five welds.

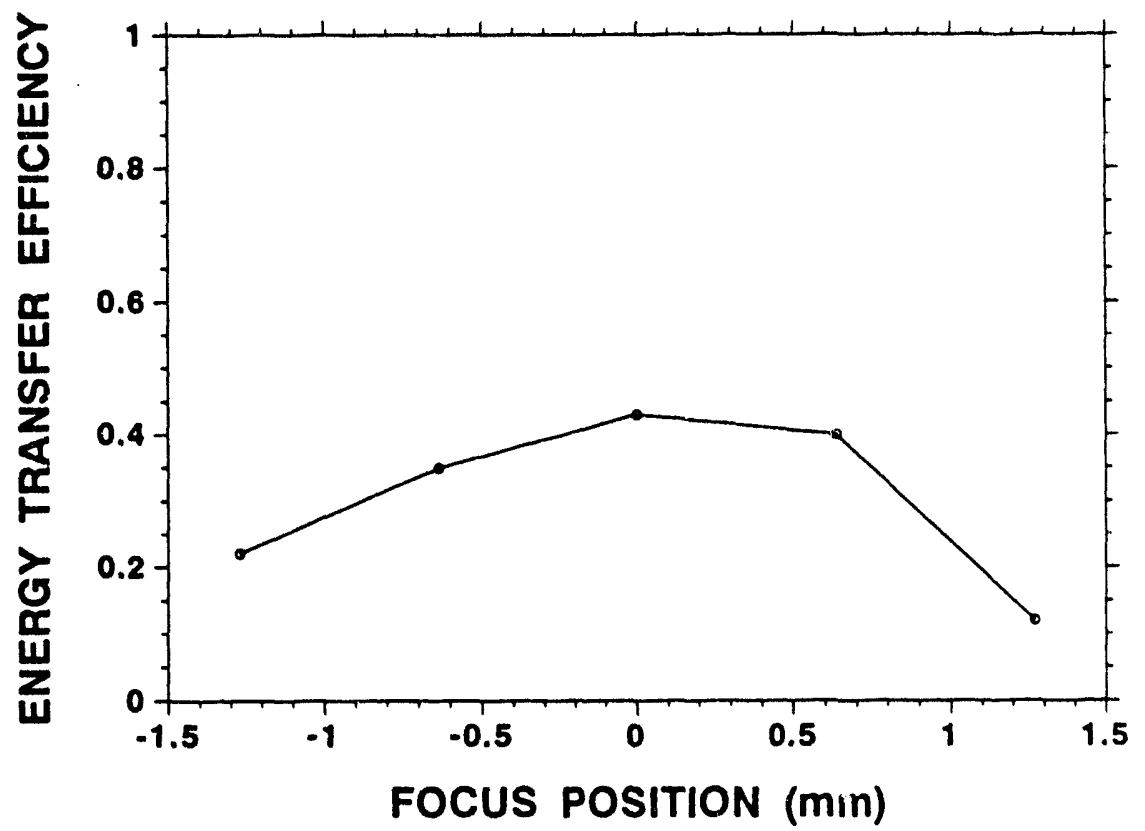

Fig. 4-Calculated laser beam absorption for CW CO2 laser welds on 304 SS at $550 W$.

One can conclude from Fig. 4 that as the laser spotsize increases about the focal plane of the lens, the energy transferred to the work decreases. This is important for laser welding application engineers to note-defocusing the laser beam results in less power absorbed by the workpiece. One may also note that the energy transfer efficiencies given in Fig. 4 are significantly lower than the 0.87 value found for the weld in example \#1. The reason for this difference is because the weld in example \#1 was made with a 2.5 in focal length lens and the weld in example \#2 was made with a 5.0 in focal length lens. Even at the sharpest focus position the beam intensity used in example \#2 is significantly less than in example \#1 which results in a much smaller fraction of the incident laser power being absorbed.

\section{Example \#3}

Often when new weld schedules are developed, the required laser process parameters must be determined in order to maximize manufacturing throughput and to minimize the thermal distortion of the part. If one develops a full power weld schedule that results in a very high energy transfer efficiency, then the entire power capability of that laser is utilized and manufacturing feedrates are also maximized for that laser system. Ultimately, the smallest laser possible (and least expensive) can be used. If this weld schedule also has a high melting efficiency, then heat input to the part is minimized and thermal distortion is reduced. A high 
melting efficiency means that all of the heat absorbed by the part is necessary and that no further reduction in heat input can be achieved. Clearly these two efficiencies are important figures of merit that should be considered during weld schedule development.

Laser welding of aluminum is an application where optimizing these efficiencies is especially important. Figure 5 shows a metallographic cross-section of a laser weld made with a high power CW Nd:YAG laser. In this application on 6061 aluminum the laser was operated close to it's maximum power and with a very small focus spotsize obtained with a 2.0 in focal length multielement lens. Despite these efforts, extremely poor efficiencies were realized as shown below:

$\begin{array}{ll}\text { Material: } & 6061 \text { aluminum } \\ \text { Enthalpy: } & \delta h=2.86 \mathrm{~J} / \mathrm{mm}^{3} \text { (Ref. 7) } \\ \text { Thermal Diff.: } & \alpha=31.7 \mathrm{~mm}^{2} / \mathrm{s} \text { (Ref. 5) } \\ \text { Output Power: } & q_{0}=1600 \mathrm{~W} \\ \text { Travel Speed: } & v=12.7 \mathrm{~mm} / \mathrm{s} \\ \text { Weld Area: } & A=0.84 \mathrm{~mm}^{2} \\ \text { Input Power: } & q_{i}=360 \mathrm{~W} \\ \text { Energy transfer Eff.: } & \eta_{t}=0.22 \\ \text { Melting Eff. } & \eta_{m}=0.08\end{array}$

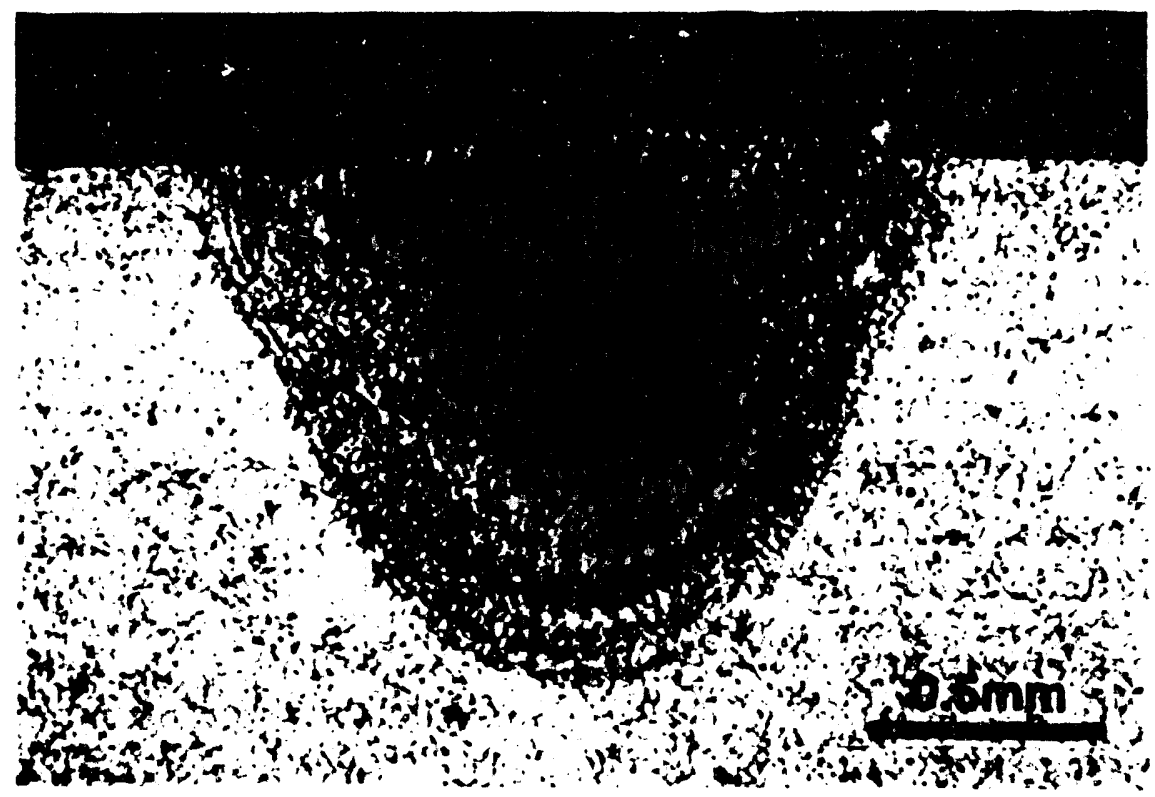

Fig. 5-Metallographic cross-section of CW Nd:YAG
laser weld used in example \#3.

These results indicate that the full power of this laser has not yet been fully utilized and that higher laser beam intensity needs to be obtained in order to increase the energy absorption and increase the travel speed. Certainly the high reflectivity of aluminum contributes to the low energy transfer. One should also note that the high thermal diffusivity of aluminum in comparison to the 304 SS of example \#1, also contributes to a very low melting efficiency in this example. Both these efficiencies will be improved if $q_{i}$ can be increased.

\section{Summary}

The above examples illustrate the important information available from laser welds when dimensional analysis is applied. While the model given in Fig. 1 is not perfect, it has been 
verified for several widely different materials and should prove beneficial in most applications. It is especially important that an accurate measurement of laser power and weld area be made. While accurate experimental data can be readily obtained, in many cases reliable thermal property data is not available and is requisite for success with this type analysis. A detailed uncertainty analysis for these type calculations is given in (Ref. 2).

\section{Acknowledgments}

The author wishes to acknowledge the excellent technical support of Fred Hooper and Jim Bullen. I would also like to thank Gerald Knorovsky and David Keicher for their valuable contributions to this work. This work performed at Sandia National Laboratories supported by the U.S. Dept. of Energy under contract number DE-AC04-94AL85000.

\section{References}

1. Swift-Hook, D. T.; Gick, A. E. F. 1973. Penetration Welding with Lasers. Welding Journal 52(11):492s-499s.

2. Fuerschbach, P. W. 1994. Measurement and Prediction of Energy Transfer Efficiency in Laser Beam Welding. submitted to Welding Journal.

3. Rykalin, N. N. 1951. Calculation of Heat Flow in Welding; Translated by Zvi Paley and C. M. Adams Jr.: Moscow.

4. Christensen, N.; Davies, V. L.; Gjermundsen, K. 1965. Distribution of Temperatures in Arc Welding. British Welding Journal 12(12):54-75.

5. Pehlke, R. D.; Jeyarajan, A.; Wada, H. 1982. Summary of Thermal Properties for Casting Alloys and Mold Materials, National Science Foundation, NSF/MEA-82028.

6. Leibowitz, L.; al, e. 1976. Properties for LMFBR Safety Analysis, Argonne National Labs, ANL-CEN-RSD-76-1.

7. Kelley, K. K. 1960. Contributions to the Data on Theoretical Metallurgy; U.S. Bureau of Mines: Washington, D.C., Vol. Bulletin 584.

\section{DISCLAIMER}

\footnotetext{
This report was prepared as an account of work sponsored by an agency of the United States Government. Neither the United States Government nor any agency thereof, nor any of their employees, makes any warranty, express or implied, or assumes any legal liability or responsibility for the accuracy, completeness, or usefulness of any information, apparatus, product, or process disclosed, or represents that its use would not infringe privately owned rights. Reference herein to any specific commercial product, process, or service by trade name, trademark, manufacturer, or otherwise does not necessarily constitute or imply its endorsement, recommendation, or favoring by the United States Government or any agency thereof. The views and opinions of authors expressed herein do not necessarily state or reflect those of the United States Government or any agency thereof.
} 

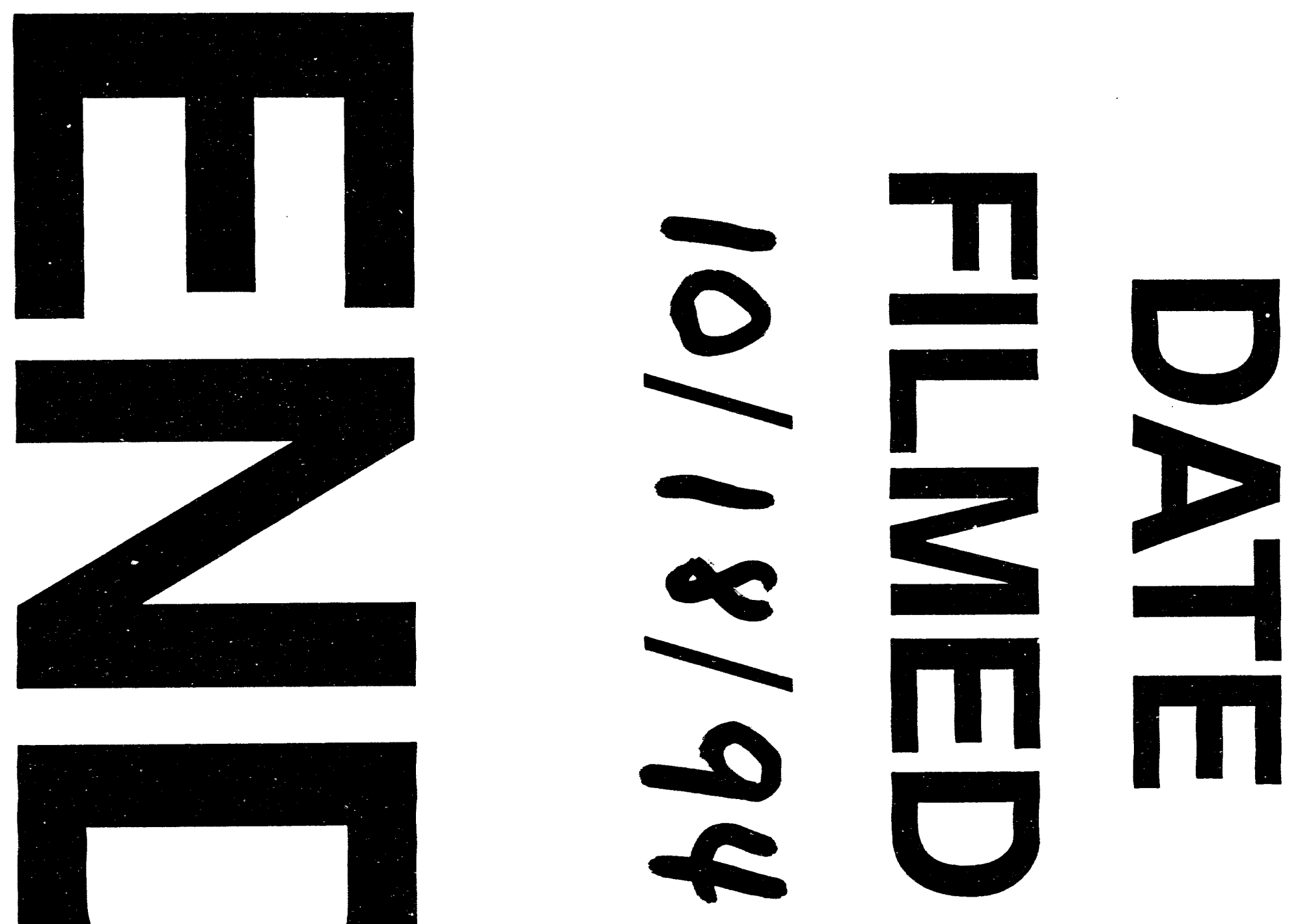
